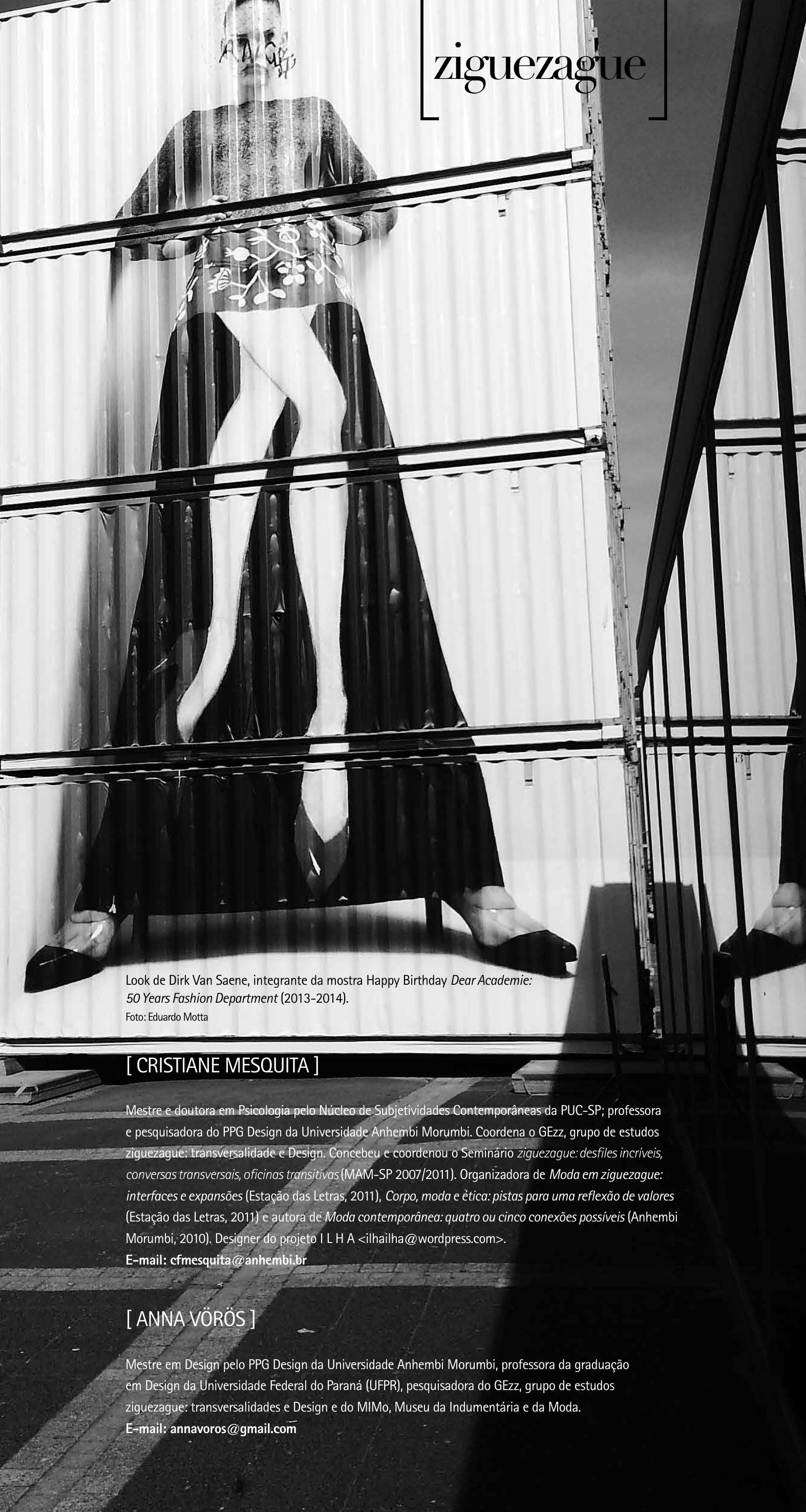




\section{Design de moda belga em ziguezague com Karen Van Godtsenhoven}

0 ziguezague' realizou uma edição extraordinária ${ }^{2}$ das Conversas Transversais para receber Karen van Godtsenhoven - curadora do Museu de Moda da Antuérpia $(\mathrm{MoMu})^{3}$. Há sete anos à frente de um dos mais importantes museus de moda do mundo, ela vem realizando a curadoria de diversas exposições e publicações. Antes disso, Van Godtsenhoven trabalhou como pesquisadora para a Comissão Europeia na Universidade de Ghent e como free-lancer para diferentes jornais, revistas e blogs. É formada em Inglês, Literatura Comparada e Museologia, mas por hora sua especialidade é o design de moda belga e a Escola de Moda da Antuérpia4.

Isso não é pouca coisa: a Bélgica e, mais especialmente a cidade de Antuérpia, evocam fascínio quando se pensa em criação e experimentação em design e imagem de moda. Na década de 1980, seis nomes fortes em autoria partiram desta escola para mostrar seus trabalhos à imprensa inglesa e tornaram-se internacionalmente reconhecidos. Desde então, a história dos polos criadores de moda e das referências estilísticas mundiais nunca mais foi a mesma. 0 grupo The Antwerp Six ${ }^{5}$ formado pelos designers Ann Demeulemeester, Dirk Bikkembergs, Dirk Van Saene, Dries Van Noten, Marina Yee e Walter Van Beirendonck - demarcou a configuração de um território de criação singular, que até hoje perdura. Para falar do museu que coordena, Karen retomou a história da Escola de Moda da Antuérpia e colocou em pauta diversos aspectos socioculturais, econômicos e políticos que revelam algumas das principais razões de um fato inusitado: uma cidade pitoresca, localizada em um pequeno pais, originou um movimento de deslocamento de referências - anteriormente concentradas em Paris, Milão ou Nova York - justamente pela radicalidade na experimentação de seus protagonistas.

É sua abordagem que apresentaremos neste ziguezague, a partir da transcrição e edição dos principais apontamentos da curadora ${ }^{6}$.

\section{Dear Academie e a singularidade belga}

Segundo Van Godtsenhoven, o "pequeno milagre da moda belga" encontra suas raizes na educação, especialmente quando da criação do Departamento de Moda na Royal Academy of Fine Arts, em 19637. Fundada no âmbito das artes aplicadas, a Escola de Moda da Antuérpia vem desde então propiciando àqueles que ali estudam um percurso de aprendizagem que enfatiza a criação, por meio de uma busca pessoal radical e sensivel.

Ao longo de 50 anos de história, a escola teve três diretores, cada qual realçando diretrizes especificas. Mary Prijot ${ }^{8}$, pintora e primeira diretora, enfatizou o ensino da moda como um tipo de educação em arte. Seu foco estava no desenvolvimento de uma linguagem visual e na criação de um repertório artistico particular. Nesse periodo, o foco não estava nas habilidades técnicas ou comerciais e "os estudantes estavam aprendendo a criar uma assinatura". Linda Loppa9 , figura impar para a história da escola, tornou-se diretora em 1985. Entre suas diversas realizações, destacam-se a abertura de espaço para o espírito avant-garde e para novas concepções de moda; o forte estímulo em direção à nacionalização da moda belga em ações do governo e, ao mesmo tempo, o impulso à internacionalização da escola. 0 atual diretor, Walter Van Beirendonck ${ }^{10}$, está à frente da escola desde 2006. 0 designer e professor deu continuidade à visão de Loppa e fortaleceu a ênfase no processo de criação individual e na radicalidade experimental. 0 ponto em comum entre os três diretores está justamente no estímulo à experimentação, ponto-chave da proposta de aprendizagem. Os estudantes são intensamente incentivados a catalisar sua individualidade para criar. Esta ênfase possibilita 
uma ruptura de fronteiras geográficas e faz com que qualquer estudante, belga ou estrangeiro, se integre intimamente ao processo educacional da escola e fortaleça sua formação: "a identidade da moda belga não está necessariamente relacionada à origem do designer, mas sim relacionada às diretrizes da escola". Esta escola é o cerne da criação de uma gama de características que definem a moda belga e esteve na base de um processo transformador, que deslocou o eixo das referências de moda.

Para além da educação, vale abordar também o contexto deste país de paisagens intensas e desta cidade de aspectos históricos e geográficos peculiares, onde se configura a "identidade de moda belga". A Antuérpia é um dos portos mais significativos do continente. Porta de entrada da Europa, teve seu auge nos séculos XVI e XVII, quando se estabeleceu como o centro da rota do mercado de diamantes e de têxteis, por abrigar uma grande indústria de tingimento. Nesse período, Peter Paul Rubens ${ }^{11}$ destacou-se entre os artistas, tornando-se grande representante da cultura barroca. Além disso, o país foi colonizado por diferentes povos, o que motivou o surgimento de "uma sensação de falta de identidade cultural". Karen pontua: "os belgas não têm nenhum tipo de orgulho nacionalista, pois nossa cultura foi sobreposta pelos austríacos, pelos espanhóis, pelos franceses e, até mesmo, pelos holandeses e alemães. Além disso, a Bélgica é ladeada por grandes centros de moda, como Paris e Londres".

Do ponto de vista cultural, o design de moda é um vetor potencial de formação da identidade de um país, juntamente com os costumes locais e outros setores criativos como a arquitetura, a arte, a literatura e a música. Para além do valor econômico, é o valor simbólico que repercute na configuração de uma identidade local: "a moda diz respeito a contar histórias por meio do que vestimos e, em uma escala maior, também configura a identidade de um país". Cada sociedade está relacionada à economia criativa de modo peculiar, a partir do encadeamento de forças particulares. Para tanto, não há fórmulas, não há receitas, mas é fato que o fenômeno belga tornou-se possível, diante das inquietações daqueles que ousaram estabelecer algo singular. Foi essa particularidade que abriu espaço para que a moda se expandisse como um fenômeno cultural, integrando-a às diversas forças que formam a imagem da Bélgica.

Foi em meados dos anos 1970, com a decadência da indústria têxtil, que o governo belga iniciou um movimento de fundamental importância: criou um plano estratégico para o setor com a pretensão de estabelecer uma relação entre a Escola de Moda e a indústria, que perdurou entre 1981 e 1987. Este plano vislumbrava também estabelecer uma nova imagem de moda que "não fosse vergonhosa diante das grandes marcas italianas e francesas" - palavras de Karen a respeito do sentimento que se fazia presente diante da proximidade do país aos grandes centros de moda europeus.

A relação entre escola e indústria têxtil contemplou a criação e a manutenção de um pequeno espaço com máquinas de costura, que promoveu o concurso Golden Spindle, direcionado para despontar jovens talentos. Os ganhadores do concurso não recebiam prêmios em dinheiro, mas uma estrutura para criar um desfile por ano. Além disso, a coleção vencedora do concurso era apresentada na revista This is Belgium, ao lado do trabalho de outros designers consagrados. 0 concurso foi um fator fundamental para o surgimento de uma nova geração de profissionais, pois, a cada competição, os concorrentes eram obrigados a repensar a moda e apresentar inovações. Portanto, à medida que ganhavam várias competições, os estudantes tornavam-se mais confiantes para delinear a configuração da moda belga. Além da diretora da escola Linda Loppa, outros nomes importantes em termos de suporte e espírito visionário foram Helena Ravijst - que organizou a campanha governamental - e Geert Bruloot ${ }^{12}$,

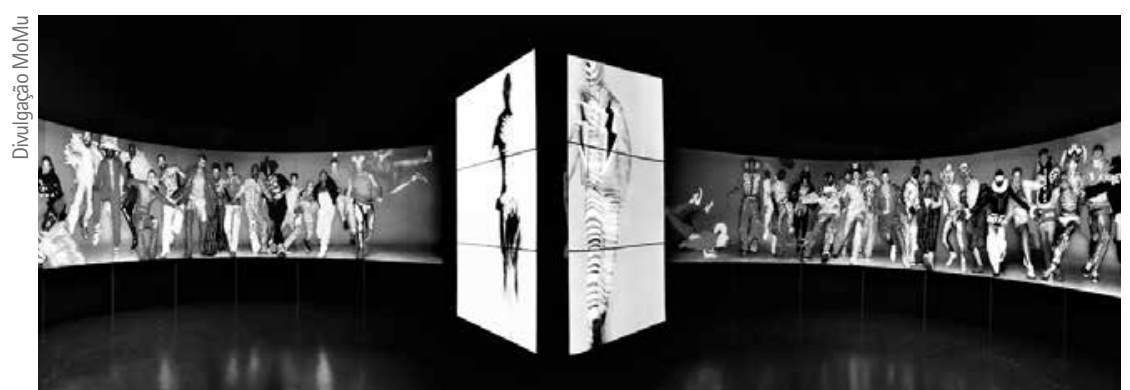

Looks e espaço expositivo da mostra Dream the World Awake (2012), retrospectiva do designer Walter Van Beirendonck. 
proprietário da Louis, primeira loja a comercializar os produtos dos novos criadores na Bélgica. Foi neste período que se formou o grupo The Antwerp Six. Os estudantes que formaram esse grupo foram alunos de Linda Loppa e se graduaram no período em que a escola estava sob a direção de Madame Prijot. Entretanto, queriam fazer as coisas fora dos padrões estabelecidos, descobrir novos modelos e desafiar as diretrizes das tendências de moda. Entre o período da formatura, em 1981, até 1986, Ann Demeulemeester, Dirk Bikkermbergs, Dirk Van Saene, Dries Van Noten, Marina Yee e Walter Van Beirendonck estavam trabalhando na indústria têxtil ou em pequenas marcas de moda locais. Martin Margiela, considerado o sétimo componente dos Six, se formou em outro ano. Trabalhou com o grupo durante a faculdade, porém não estava na formação oficial, pois recebeu convite para trabalhar para o estilista francês Jean-Paul Gaultier, em 1984. Os Seis da Antuérpia participaram do Golden Spindle, embora tenham se rebelado contra os direcionamentos do plano de governo, pois queriam "revirar a roupa, desconstruí-la e remexê-la - o que não condizia com o padrão que muitos vislumbravam estabelecer para a indústria belga". Após a conquista de várias premiações, e sob o olhar de Geert Bruloot, o grupo foi a Londres, em 1986, e encontrou espaço fértil para mostrar suas ideias. Embora estivessem no segundo andar de uma mostra de roupas de noivas, um editor da Revista $i-D^{13}$ percebeu a extrema qualidade das criações avant-garde e ali foram descobertos para o mundo: "eles estavam em sintonia com a cultura jovem da Europa, que, naquele momento, desejava ver algo novo e diferente daquilo que as maisons francesas mostravam".

Ao longo da existência da escola, formou-se uma pequena comunidade criativa em torno do design de moda. Muitas dessas pessoas são estudantes ou ex-alunos da Academia de Artes. São fotógrafos, artistas, stylists, maquiadores e designers gráficos que trabalham juntos dos designers de moda. Essa atmosfera de colaboração é outro fator muito importante para criar e sustentar uma imagem de moda para o pais. Alguns desses profissionais trabalham em grandes maisons, mas, paralelamente, mantém seu trabalho autoral e coletivo na Bélgica. Entre eles estão a dupla Olivier Rizzo e Willy Vanderperre, designer e fotógrafo; o diretor criativo Peter Phillips; o designer gráfico Paul Boudens e o arquiteto Bob Verhelst. Este último foi braço direito de Martin Margiela. Juntos, criaram o design típico da Maison Martin Margiela e o interior das lojas, com efeitos tromp l'oiel. Margiela tem sua própria assinatura, mas foi com essa parceria que criou todo um universo conceitual. 0 casal Inge Grognar - maquiadora artística - e Ronaldo Stoops fotógrafo - também produziram juntos imagens muito fortes para Margiela.

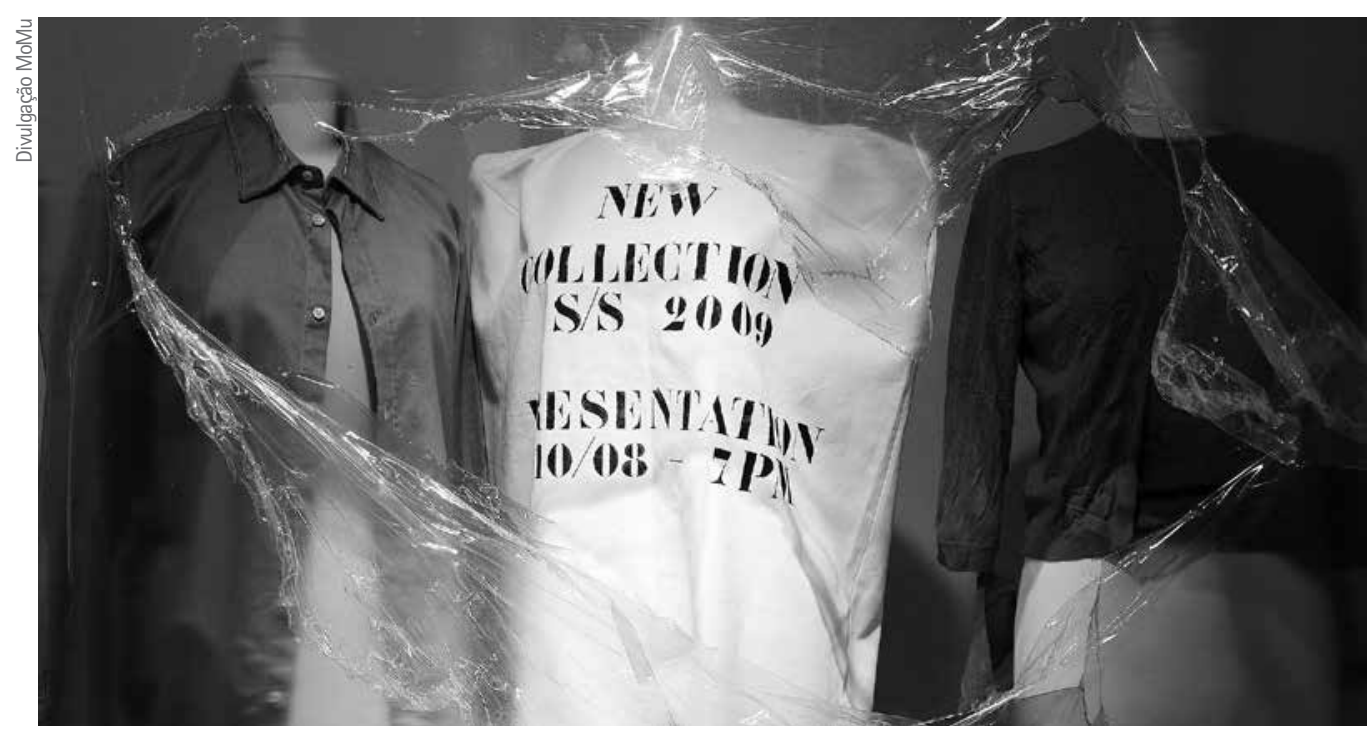

Look integrante da exposição Maison Martin Margiela 20: the exihibition (2008-2009).

Passado o boom do Grupo dos Seis, vários outros designers belgas oriundos da escola despontaram no cenário internacional da moda contemporânea. Vale mencionar Veronique Branquinho, que tem raizes portuguesas; o alemão Bernard Willhem e Peter Pilotto, que são da segunda geração; A. F. Vandevorst - um casal conhecido por suas referências ao artista alemão Joseph Beuys ${ }^{14}$ e ao mundo da medicina; e Haider Ackermann, um dos criadores que faz parte da nova geração. E assim a Antuérpia perdura como uma cidade que vibra moda: "é uma cidade universal em um país universal. 
Nós estamos perto de vários grandes centros de moda como Paris e Londres e, ainda assim, fomos capazes de criar uma distinção diversa da moda reconhecida como 'italiana' ou 'francesa'. E não somos ofuscados por ela".

\section{As diretrizes curatoriais do $\mathrm{MoMu}$}

Após o auge criativo do design de moda e sua consolidação, ao longo dos anos 1990, Linda Loppa frisou a necessidade de se criar uma estrutura arquitetônica para acolher e fomentar o fluxo em ascensão. Assim, em 2002, fundou o MoMu - no prédio onde antes havia o museu de têxteis - no centro da cidade.

Seu acervo ${ }^{15}$ contempla 25 mil objetos, parte dele de caráter histórico e parte de produção contemporânea. 0 Museu de Moda da Antuérpia congrega a Escola de Moda, o acervo e um instituto de apoio comercial aos designers, caracterizando-se assim como um espaço que serve tanto aos profissionais e estudantes, quanto aos visitantes. Em dez anos de existência, completados em 2013, recebe aproximadamente 90 mil visitantes por ano. A maioria é de turistas europeus, mas recentemente percebeu-se um fluxo de pessoas de fora da Europa que estão buscando algo diverso daquilo que se vê em Paris ou em Londres. Visto que não se pode visitar os ateliês dos designers belgas, o MoMu representa um espaço acessivel, onde estão disponíveis peças, informações e imagens de forma sistematizada. 0 acervo está organizado na biblioteca do museu, para disponibilizar o contato com as roupas, que podem ser examinadas em detalhes sobre estrutura, modelagem e costura. Além disso, os pesquisadores e estudantes podem consultar virtualmente os projetos das roupas. 0 museu criou um programa voltado para estudantes com idade de 4 a 18 anos, pois um terço dos contingente de visitantes é formado por escolas. A maioria das exposições é focada em designers de moda belgas, mas a intenção curatorial é "mostrar que na moda vários sonhos estão conectados e mudam todo o tempo. Portanto, propomos uma ligação histórica com a moda atual", afirma Van Godtsenhoven. Algumas coleções de estudantes da Escola de Moda também são exibidas na galeria do museu, em suporte multimídia.

A concepção das exposições é coletiva desde o princípio, de modo que seja traçado um conceito que reunirá aspectos da exibição das roupas, da arquitetura e das particularidades da montagem. Nesse sentido, todos os profissionais envolvidos atuam juntos e, muitas vezes, o criador de moda que será tema da mostra é convidado a fazer parte da equipe. Assim, pretende-se delinear uma atmosfera que conecta a criação da coleção à sua exibição no espaço do museu. Outro ponto vital é a valorização do aspecto narrativo da moda, no sentido de afirmá-la como um modo de expressar subjetividades e de contar histórias: "o MoMu procura dar vida às coleções, ao invés de exibi-las de modo estático, como se fossem vitrines. Assim, procuramos conferir singularidade a cada exposição. Mesmo que a mostra seja exibida em outras instituições, procuramos preservar a identidade proposta, pois isso exalta o valor simbólico, capaz de revelar aspectos do contexto econômico, político e cultural, que diz respeito ao criador e ao âmbito coletivo".

A frequência média de exposições é de duas por ano, e o museu já soma 21 realizações ${ }^{16}$, entre elas Maison Martin Margiela 20: the exhibition (2008-2009), sobre os vinte anos de trabalho do designer belga; Dreamshop: Yojhi Yamamoto (2006), retrospectiva da obra do criador japonês; Bernhard Willhelm: total recall (2007-2008), sobre o trabalho do designer de origem alemã formado na Bélgica; e Stephen Jones \& the accent of fashion (2010-2011), com o trabalho do designer inglês de chapéus. Uma das exposições mais emblemáticas foi Dream the world awake (2012), com as criações do belga Walter Van Beirendonck, atual diretor da Escola de Moda da Antuérpia e integrante do Grupo dos Seis. Nesse projeto, acessível pelo website ShowStudio ${ }^{17}$, além das roupas e de vídeos que apresentavam as peças vestidas, 0 ateliê do designer foi recriado e exibiu sua coleção de mais de mil brinquedos e um registro de imagens que mostra como ele desenha suas peças.

Entre as exposições de designers são intercaladas mostras temáticas, cujos disparadores são escolhidos pela equipe do MoMu. Cores, técnicas e matérias-primas empregadas no design de moda podem ser o mote para compor e conceituar um conjunto de peças e de objetos que compreende diferentes linhas de criação e diversos períodos históricos sobre o tema. Um exemplo é a exposição Black: masters of black in fashion and costume (2010), na qual pinturas, roupas e acessórios de cor preta ocuparam o museu. Vitor\&Rolf, Raf Simons, Alexander McQueen, Comme des Garçons 
foram alguns dos participantes. Outra exposição temática foi Unravel: knitwear in fashion (2011), que mostrou trabalhos em tricô realizados por diversos designers. Uma das últimas exposições temáticas foi intitulada Madame Grès sculptural fashion (2012-2013) e apresentou o trabalho de uma das damas da alta-costura de Paris, na década de 1930. 0 cunho escultórico da mostra esteve em sintonia com o trabalho da estilista, que primava por suas construções formais. Esse tipo de ressonância faz parte da filosofia do MoMu: "é muito bom que um museu de moda possa contribuir por meio de um espaço que conte histórias, para além das imagens de catálogos ou das passarelas. E trabalhamos para não ser vitrines estáticas, mas sim para funcionar como uma plataforma para os designers. Pretendemos ser uma instituição dinâmica que promova interação e enriqueça referências, em diversos sentidos".

Ao encaminhar o final da Conversa transversal, a curadora mencionou 0 andamento do projeto Happy Birthday Dear Academie: 50 years fashion department (20132014), exposição sobre os 50 anos da Escola de Moda da Antuérpia, inaugurada no final de 2013. Este grande projeto contemplou seis locações na cidade, ocupando edifícios históricos, espaços públicos e ruas, além de projetos online que deram suporte às exposições ${ }^{18}$. Sobre novos planos, Karen apontou a criação de um projeto que incentivará novos designers e curadores a colaborar com as propostas e com a elaboração das exposições. Ao narrar suas impressões sobre a visita ao Brasil, aponta que "qualquer pais tem potencial para desenvolver produtivamente uma identidade em design de moda, mesmo os mais improváveis como a Bélgica", e retoma a ênfase no aspecto educacional que estimula a experimentação e a criação e na necessidade de incentivo e apoio governamental: "a moda conta histórias sobre uma pessoa. Ou sobre uma nação".

\section{NOTAS}

[1] Disponivel em: <http://ziguezagueblog.wordpress.com>. Acesso em: 28 out. 2014.

[2] Evento ocorrido em 23 de abril de 2013 no Centro Cultural Banco do Brasil (CCBB) de São Paulo, com mediação de Cristiane Mesquita e Eduardo Motta. A conversa teve traducão consecutiva realizada por André Monteiro. Realização do evento: CCBB; Grupo de Estudos ziguezague - PPG Design da Universidade Anhembi Morumbi; RADAR - inteligência e projetos de moda. Apoio: Centro Universitário Belas Artes; CAPES; Circuito de Moda e Arte; CNPq; Estação das Letras e Cores; Farinha Produções; Galeria Central.

${ }^{[3]}$ Mode Museum Provincie Antwerpen. Disponível em: <http://www.momu.be>. Acesso em: 28 out. 2014.

${ }^{[4]}$ Disponivel em: <http://www.antwerp-fashion.be>. Acesso em: 28 out. 2014.

${ }^{[5]}$ Disponível em: <http://antwerpsix.blogspot.com.br/> Acesso em: 28 out. 2014.

${ }^{[6]}$ Os trechos entre aspas ao longo do texto são citações literais de Karen Van Godtsenhoven na Conversa transversal do ziguezague: edição extraordinária.

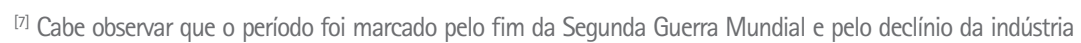
têxtil em Flandres.

${ }^{[8]}$ Duddeston, 6 de abril de 1917 - Antuérpia, 24 de julho de 1998.

[9] Nascida em Antuérpia, graduada em Design de Moda na Royal Academy of Fine Arts em 1971. Disponivel em: <http:// <http://www.contemporaryfashion.net/index.php/none/none/423/uk/profile.html>. Acesso em: 28 out. 2014

${ }^{\text {[10] }}$ Nascido em Brecht, em 4 de fevereiro de 1957. Disponivel em: <http://www.waltervanbeirendonck.com/>. Acesso em: 28 out 2014.

[11] Pintor flamengo que manteve seu estúdio na Antuérpia no início do século XVII (Siegen, 28 de junho de 1577-Antuérpia, 30 de maio de 1640).

${ }^{[12]}$ Mais tarde, Bruloot foi importante para a criação do MoMu e do Instituto de Moda de Flandres.

${ }^{[13]}$ Disponivel em: <http://i-d.vice.com>. Acesso em: 28 out. 2014.

${ }^{[14]}$ Krefeld, 12 de maio de 1921-Düsseldorf, 23 de janeiro de 1986.

${ }^{[15]}$ Acervo do museu. Disponivel em <http://www.europeanafashion.eu> Acesso em: 28 out. 2014.

${ }^{[16]}$ Arquivo das exposições e acervo do MoMu. Disponivel em: <http://www.momu.be/en/Exhibitions/archive. $\mathrm{html}>\mathrm{e}<$ www.europoeanafashion.eu>. Acesso em: 28 out. 2014.

${ }^{[17]}$ Disponivel em: <http://showstudio.com/project/dream_the_world_awake>. Acesso em: 28 out. 2014.

${ }^{[18]}$ Disponivel em:<http://www.happybirthdaydearacademie.be>. Acesso em: 28 out. 2014.

\section{REFERÊNCIAS}

(que apoiam a edição da Conversa transversal com Karen Van Godtsenhoven)

BIERENDONCK, Walter van; DERYCKE, Luc (Ed.). Fashion 2001, landed geland \#1. BRUGEs: Merz: Antwerpen Open: Flanders Fashion Institute, 2001.

DERRYACKE, Luc; VAN DE VEIRE, Sandra (Ed.). Belgian fashion design. Ludion, 2000.

WILCOX, Claire (Editor). Radical Fashion. London: V\&A Publications, 2001. 